International Journal of Child, Youth and Family Studies (2011) 3 \& 4: 361-384

\title{
ALL CHILDREN ARE EQUAL, BUT SOME ARE MORE EQUAL THAN OTHERS: MINORITIZATION, STRUCTURAL INEQUITIES, AND SOCIAL JUSTICE PRAXIS IN RESIDENTIAL CARE
}

\section{Sandrina de Finney, Mackenzie Dean, Elicia Loiselle, and Johanne Saraceno}

\begin{abstract}
This article draws on our practice and research experience in diverse residential settings to examine structural inequities facing children and youth in residential care. Our overall goal is to conceptualize residential care as a site for radical advocacy and social change. We track the impact of minoritization by exploring links between historical structural inequities and the positioning of minoritized groups as being in need of professional intervention. Drawing on queer, anti-racist, Indigenous, postcolonial, and feminist theories, we explore how interplaying processes of racialization, gendering, classing, and sexualization (among others) produce unequal circumstances for some groups of children and youth in residential care. We situate our critique in an analysis of two important structural forces that shape contemporary social services in the West: neoliberalism and neocolonialism. We propose that employing a critical social justice analysis in our engagement with children, youth, families, and communities - and with the systems in which they and we are embedded - can open alternative possibilities for residential care praxis.
\end{abstract}

Keywords: Child and youth care, residential care, social justice/injustice, child welfare, diversity

Correspondence should be addressed to Dr. Sandrina de Finney.

Sandrina de Finney, Ph.D. is Assistant Professor in the School of Child and Youth Care, University of Victoria, P.O. Box 1700, STN CSC, Victoria BC Canada, V8W 2Y2. sdefinn@uvic.ca

Mackenzie Dean is a graduate student in the School of Child and Youth Care at the University of Victoria.mldean@uvic.ca

Elicia Loiselle is a graduate student in the School of Child and Youth Care at the University of Victoria. elicia@uvic.ca

Johanne Saraceno is a graduate student in the School of Child and Youth Care at the University of Victoria. jsaracen@uvic.ca 
International Journal of Child, Youth and Family Studies (2011) 3 \& 4: 361-384

It's like our story that we had as natives. My whole family's been in the system, like seriously, my whole family, my brothers, cousins, aunts, all that . . . and my parents were in the residential schools. The same story that gets passed down from each generation. ... It's really, really sad because you kinda think, it makes you think like . . . why us?

(Dylan, First Nations youth in care) ${ }^{1}$

Certain groups of children and youth - Indigenous, racialized minority, queer, poor, and those with disabilities and special needs - are chronically overrepresented in residential care settings. Why? Why are they and their families so often depicted as inherently deficient and blamed for inequities over which they have little control? And what is the responsibility of residential care practitioners to intervene in these inequities?

In this article, we consider these important questions through a critical exploration of structural inequities in the lives of children and youth in residential (out-of-home) care in a Canadian context. Our focus is the minoritization ${ }^{2}$ of children and youth who fall outside of white, heterosexual, able, middle-class norms, and who, as a result, face high indicators of social exclusion such as poverty, racism, and homophobia, and are chronically overrepresented in residential care. We focus on residential care settings because they are microcosms of the ideologies, practices, and policies that guide social services for those children, youth, and families most often characterized as "at risk". We propose two goals with this article: first, to problematize the systemic minoritization of certain groups of children and youth to understand their overrepresentation in residential care; and second, to contribute to the conceptualization initiated by others (see, for example, Gharabaghi, 2009; Newbury, 2009; Reynolds, 2010; SkottMyhre, 2004, 2008) of child, youth, and family services as a site for radical theorizing, advocacy, and social change.

Our analysis is grounded in our own experiences as queer and First Nations child and youth care (CYC) practitioners and researchers. In this article, we include quotes and examples shared with us in our work with practitioners and minoritized children, youth, and families in diverse rural and urban out-of-home and residential care settings in Canada. We track minoritization's impact by exploring links between structural inequities and the positioning of minoritized children and youth as being in need of professional intervention. We question why those who fall outside of normative white, heterosexual, able, middle-class ideals of family and childhood are so drastically overrepresented in residential care. Our critical exploration of minoritization shows that, in fact, who ends up in care and why they end up there is neither a coincidence nor the exclusive result of individual failings, but rather is an outcome of a system designed to reproduce normative roles for children, youth, and families and for those who serve them. We situate our critique in an analysis of the two most important structural forces to have

\footnotetext{
${ }^{1}$ The descriptors used for the quotes vary according to how each speaker has chosen to be identified.

${ }^{2}$ Minoritized groups are positioned as outsiders to dominant norms and consequently seen to fall short of the standards of the dominant group. When difference is the basis for exclusion, a social context is created where certain groups are privileged and others subjugated or minoritized (i.e., seen as "less than" or "other”) based on their positioning in a normative social hierarchy (Harley, Jolivette, McCormick, \& Tice, 2002). These exclusions produce drastically unequal outcomes for certain groups of children, youth, and families.
} 
shaped contemporary life (and thus social services) in the West - neoliberalism ${ }^{3}$ and neocolonialism. ${ }^{4}$ To show how ideas about normativity (i.e., what is considered normal) are intimately linked to neoliberalism and neocolonialism in Canada, we apply our analysis to an indepth exploration of the overrepresentation of Indigenous children in care.

Next, we problematize the taken-for-granted roles of the residential care system and its service providers in reproducing the systemic minoritization of certain groups. Our goal in putting forth this analysis is to trouble the positioning of our work with children, youth, and families as inherently benevolent. We question why the residential care system generally fails to target structural inequities and instead equips service providers with tools to help clients "fit" and "rehabilitate" into normative standards of health, wellness, development, and family. These standards are problematic, first, because they so often remain elusive to minoritized individuals who are marked as irrevocably outside the norm, and second, because they fail to acknowledge that minoritized communities may have quite different goals and values for their own development. In dealing with these complexities, the notion of diversity competencies in which residential care is often grounded proves woefully inadequate; in fact, diversity competencies may reproduce historical inequities by constructing “diversity experts”. We argue that this construct offers an illusion of competency centred on reifying problematic, superficial notions of culture rather than on addressing systemic issues such as those that contribute to racialization, sexualization, and heteronormativity.

In our final section, we explore how employing a more critical, politicized analysis in our engagement with children, youth, and families in care might open alternative possibilities of praxis ${ }^{5}$ to support us in responding to structural inequities and processes of minoritization. We contest concerns - familiar in an applied field such as ours - that critical analysis detracts from practice. We argue that ignoring links between social inequities and the realities of children and youth in care reasserts the dominance of Euro-Western psychological norms and inevitably reproduces processes of minoritization that are so harmful to the communities we work with. It is to this dilemma that we dedicate our conclusion, not with hopes of providing a definitive answer, but rather to add complexity to easy conclusions and invite others into an ongoing dialogue.

\footnotetext{
${ }^{3}$ Neoliberalism is the dominant ideology shaping our social, economic, and political systems under globalization. Based on free market values and the supremacy of globalized corporations, it enshrines values of competition, privatization, individual responsibility, surveillance, and managerialism (Phoenix, 2004). Neoliberalism is posited on the notion that everybody has equal opportunities to succeed. "What is most discouraging is the sense most people have that not only is there no other alternative, but that this is the best system ever imagined. . . . Inequities are simply swept out of sight” (Said, 2000, p. 5, as cited in Phoenix, 2004, p. 228).

${ }^{4}$ Neocolonialism is closely linked to neoliberalism and refers to both ongoing and new forms of colonialism. In countries that remain actively colonial, such as Canada and the United States, it is inaccurate to think of colonialism as having occurred in the past. As Indigenous activist Bobby Sykes famously asked, "Post-colonialism? What? Have they left?" The progress of Canadian society continues to rely on the subjugation and relocation of entire Indigenous societies, which sustain a system of chronic poverty, social exclusion, and political and cultural disenfranchisement. Far from being resolved, many of these problems are worsening over time.

${ }^{5}$ Praxis is a way of talking about theory and practice as fundamentally interconnected and mutually constitutive. White (2007) defines praxis as "ethical, self-aware, responsive and accountable action, which reflects dimensions of knowing, doing and being” (p. 226).
} 
International Journal of Child, Youth and Family Studies (2011) 3 \& 4: 361-384

\section{Some children are more equal than others ${ }^{6}$}

Poverty is the main reason kids come into care, I think - which means that kids who are more likely to be poor are the ones we end up working with. I see a lot of Black kids, Aboriginal kids, kids with single moms. Disadvantaged kids, that's who ends up in group homes - their parents can't care for them right? So they need to be there.

(A residential care practitioner with five years experience)

Before we explore the history of residential care, it would be useful to clarify the concepts and theories that inform our analysis. Our use of the term "minoritization" conveys the effects of social relations of power in producing hierarchies of normativity that result in certain children, youth, and families being excluded from mainstream notions of well-being and success and position them as in need of professional help. The premise of our title, that some children are more equal than others, is a reference to systemic and structural inequities embedded in sociocultural, economic, and political structures (e.g., social institutions, governmental discourses and policies, human services, family systems, etc.). Rather than operating simply at an individual level, structural inequities take hold as social reality with deep-seated, systemic effects on minoritized groups. For example, "poor" and "racialized" 7 are mutually constituted; although racialized groups, particularly First Nations and recent immigrants of colour, are a demographic minority in most Canadian cities, they represent up to $75 \%$ of all children in low-income households (Access Alliance, 2007; Statistics Canada, 2003). These individuals are more likely to be poor not because of some innate characteristic, but because of the relationship between racism and economic exclusion; this relationship results in reduced access to quality housing, employment, education, social and counselling services, life skills training, recreational activities, and child and health care services, among other things (Galabuzi, 2004). The systemic exclusion of minoritized children and youth not only affects them materially, but also has consequential effects on their development and future prospects (UNICEF Canada, 2010). The unequal distribution of power and resources is a root cause of social injustices that place children, youth, and families at risk and contribute to the very conditions (poverty, family breakdown, mental health issues, substandard housing, neglect, etc.) that residential care systems hope to address. Thus minoritization is neither a natural quality nor a fixed process, but rather is socially constituting and constituted, meaning that minoritized groups "do not occupy the position of minority by virtue of some inherent property (e.g., of their body shape, culture or religion), but acquire this position as an outcome of a socio-historical process" (Chantler \& Smailes, 2004, p. 34).

To uncover how dominant social discourses operate under neocolonialism and neoliberalism, we employ a transtheoretical critical framework which integrates an analysis of

\footnotetext{
${ }^{6}$ We pay homage to George Orwell's (1945) satirical novel, Animal Farm, in which “all animals are created equal except that some are more equal than others.” We apply Orwell's critique of social hierarchies under communism to our analysis of social stratifications under neoliberalism/neocolonialism.

${ }^{7}$ We contest the notion of race as an innate biological reality and focus instead on racialization as a process which involves being categorized as different, inferior, or Other by the dominant group based on perceived sociocultural and physical characteristics such as skin and hair colour, language and accent, clothing, religious markers, citizenship status, performance and intelligence measures, and inferred "personality" traits, among others (Miles, 1997). Similar processes to racialization operate to sustain hierarchies based on economic and social class, ability, gender, and sexuality.
} 
International Journal of Child, Youth and Family Studies (2011) 3 \& 4: 361-384

power relations and subject formation (Foucault, 1978, 1980) with sexuality studies and queer theory (Charles, 2010; Renold \& Ringrose, 2008; Robinson \& Davies, 2007) and Indigenous, postcolonial, and poststructural feminisms (Grewal, 2005; Hernandez \& Rehman, 2002; Lawrence, 2004; Mohanty, 2003; Schutte, 2007; Smith, 2004). This conceptual framework helps us to unpack Euro-Western psychological theories of development that underwrite our field and scientifically "validate" dominant social discourses, such as those related to gender, sexuality, race, ability, class, and age (Burman, 1994; Morss, 1996). Skott-Myhre (2004) stresses that developmental theories have provided working models for the colonial project throughout the past 300 years. By excluding other forms of knowledge of what child development or healthy families might look like (Morss, 1996), the hegemony of Euro-Western developmental theories maintains a power imbalance that, as Pereira (2008) explains, allows the dominant group to recognize, control, and discipline minoritized groups through systems of intervention that are disconnected from their needs and realities, and reassert normative standards.

\section{Defining out-of-home and residential care}

I think the goals of residential care are to try to connect with the kids and do whatever you can to help them get out of the group home - to move back home or out on their own. Group homes aren't the best places, not ideal anyways. You want to help them get back to normal - no trouble at school, no behaviours that get them in trouble, healthy coping strategies - you know, so that they can make it on their own.

(A residential care provider with nine years experience)

Out-of-home care settings and practitioners are incredibly diverse in their goals, approaches, and policies, yet a common history and a set of principles and competencies characterize the field of residential care and those it serves. It is these commonalities upon which we focus our analysis. We recognize, however, that we use imperfect language that warrants problematization. For instance, we acknowledge that terms we use in this article such as "worker," "client," "resident," and "in care", among others, are loaded and open to debate. We choose to write through such tensions because the cost of intellectual and practical paralysis that might result from ignoring them is greater than the limitations of our analysis. We do not expect to resolve these tensions here, but rather hope to engage with them as a starting point for a radical rethinking of what praxis with the most "at risk" of minoritized children, youth, and families might look like.

Throughout history, settings have existed to provide care for children and youth who were not, for various reasons, living with and/or being provided for by their family of origin. Orphanages are an early example of what we today call out-of-home care. Anglin (2002) states that in Canada's early residential institutions, "the primary emphasis was the provision of housing and basic care for the homeless, orphaned, and impoverished. For the socially deviant, the goal was segregation from mainstream society and 'correction' ” (p. 10). Many children and youth who fell outside the norm have historically been institutionalized for the purpose of segregation and correction; for instance, children and youth with disabilities have a lengthy history of being placed in out-of-home care arrangements, particularly those known as asylums, hospitals, and treatment centres (Strong-Boag, 2007). Religious groups have also provided outof-home care. The residential schools that many Indigenous children in Canada were forced to 
attend in the 19th and 20th centuries are one such example. Administered by Christian churches, one of their primary goals was to forcefully convert "heathen Indian children" to Christianity (Lawrence, 2004). Homes for children and youth who were deemed to be socially deviant, including young unwed mothers, were also run by religious groups (Anglin, 2002). In a Canadian context, this care responsibility has become separated, for the most part, from religious organizations and now falls to government through the child welfare system.

Residential care as it is known today can be defined as settings in which children and youth live on a regular or part-time basis and where the primary intervention or "treatment" is the milieu itself (Burns, 2006). For the purpose of this article, we consider foster homes, group homes, treatment homes, institutions, and juvenile justice/custody programs all to be venues in which out-of-home care is delivered. A continuum of care is provided within these settings which ranges from the less formal foster or surrogate family approach to the more formalized institutional treatment or correctional context, where care is provided by paid professionals (Anglin, 2002). These diverse settings have traditionally been the primary site in which child and youth care practice occurred and from which its approach was first theorized (see Anglin, 2002; Maier, 1967; Trieschman, Whittaker, \& Brendtro, 1969).

Residential care programs are typically regarded as a last resort where children and youth from the most difficult circumstances are cared for so that they might benefit from the programs' presumed therapeutic value (Frensch \& Cameron, 2002). While each case is unique, these children and youth frequently have in common the experience of social exclusion based on their differences from dominant norms. Alarming statistics show that children and youth with special needs and disabilities, and those with Indigenous, racialized minority, low-income, queer and gender-nonconforming backgrounds are disproportionately present as clients within the child welfare and residential care systems when compared to the dominant population (Lavergne, Dufour, Trocmé, \& Larrivee, 2008). For example, the Representative for Children and Youth (2009) reports that in British Columbia almost $72 \%$ of youth in the youth justice system and $65 \%$ of children in continuing custody were diagnosed with a mental health disorder. The Child Welfare League of Canada (2003) reports that 3,000 young people with disabilities are taken into care each year in Canada, and, further reports that an estimated 30\% to $40 \%$ of the in-care population across Canada is Indigenous, even though Indigenous people constitute less than 5\% of the total Canadian population. Of even greater concern is the reproduction, over generations, of cycles of residential involvement, where individuals who were children in residential care are overrepresented in adult correctional and treatment facilities. In a review of longitudinal studies of outcomes for children who grow up in foster care, Fechter-Leggett and O'Brien (2010) found that "former foster children have lower educational achievement; higher rates of unemployment and underemployment; are overrepresented in the homeless; have higher rates of arrest and conviction; and suffer from more mental health issues such as PTSD, depression, and substance use than the matched comparison groups of non-foster children” (p. 207).

We do not take these statistics or their affiliated categories of identification as static and innate; we understand them as fluid and mutually produced, and reified through engagement with the system. We also know that the statistics to which we do have access fail to capture the true level to which minoritized children and youth are present in the residential care system. Child welfare regulations, for example, differ in each of the provinces and territories, leading to 
inconsistent definitions and documentation of identifiers such as "special needs" and "ethnic minority”. Also, the Canadian child welfare system is under-researched from a critical perspective, rendering processes of minoritization virtually invisible in the available data. Little information exists, for instance, about queer and gender-nonconforming ${ }^{8}$ children and youth in the Canadian child welfare system. One American organization reports, however, that $\mathrm{LGBTQ}^{9}$ youth:

are overrepresented in the foster care system, and are more likely than other foster youth to be placed in group homes and other congregate care facilities. [In addition, an] overwhelming majority of LGBTQ youth report they were victims of violence, and all have been victims of verbal abuse, based on their sexual orientation or gender identity, while in group care. (Family Builders Adoption Network, n.d., para.1)

The absence of information about children and youth who do not conform to dominant gender and sexuality norms in systems of residential care powerfully illustrates how a dominant culture of “don't ask, don’t tell”"10 effectively minoritizes young people who do not fit dominant norms of gender and sexuality. It is also important to recognize that "don't tell" is a survival strategy used by many of these children and youth to escape the very dangerous consequences of being "out", particularly within a system of care that does not recognize their existence, let alone adequately address barriers to their safety. We do know that queer youth are more likely to drop out of school and more likely to be homeless (Centre for Addiction and Mental Health, 2004). They are also more likely to contemplate or attempt suicide; an estimated 32\% of them do compared to 7\% of straight youth (Centre for Addiction and Mental Health, 2004). Heteronormativity and homophobia are inextricably linked to these negative outcomes.

Even these incomplete statistics demonstrate that minoritization and its effects are significant structural contributors to the "need" for professional intervention in the lives of these children and youth (Newbury, 2009). We acknowledge that a diversity of approaches exists among programs and care providers within the residential care sector, and that creative methods are often employed to resist dynamics of minoritization. But surely there is a common link, since the chronic and systemic overrepresentation of minoritized groups across diverse residential systems and contexts is neither coincidental nor the result of innate deficiencies. As the quote from an experienced residential care provider at the beginning of this section illustrates, a systemic analysis emphasizes that the purpose of residential programs remains firmly rooted in society's need to identify those children and youth deemed to be in need of interventions

\footnotetext{
${ }^{8}$ Just as we contest notions of race, we also problematize gender and sexuality as innate biological realities. Binary gender categories (boy/girl) reify the hierarchy of male, then female, while excluding a broad spectrum of gendernonconforming people such as transgendered or gender queer people. Similarly, heteronormativity privileges straight over bi, gay, lesbian, queer, and two-spirited sexualities, among others. Thus heterosexuality is privileged through interconnected dominant expectations of gender and sexuality (e.g., appropriate masculinity equals being tough and straight). Gender-specific programs and interventions tend to reify normative gender categories and the heteronormative status quo. This both constrains possibilities for unfixing these categories and marginalizes young people who do not identify with them.

${ }^{9}$ Lesbian, gay, bisexual, transgendered, questioning.

${ }^{10}$ Although “don't ask, don't tell” is best known as a U.S. military policy related to GLBTQ personel, it reflects a pervasive ideology of silencing and denial that is communicated to children at a very early age and is often reproduced in systems of care in a Canadian context.
} 
intended to promote their eventual reinsertion into the very societal conditions that led to their overrepresentation in care in the first place.

It is this mutual construction of "in need of care" and "care provision" that requires unpacking. We see the need to ask critical questions about how we conceptualize the entangled relationship between normativity and service provision. What are the needs of minoritized children and youth in care, and what criteria are used to determine them? Who provides this care and what do they define as appropriate or normal functioning? What does the young person, family, community, or broader society consider normal? How are alternative or contested notions of health, wellness, and development considered in planning and delivering care? What are the social inequities - such as poverty, colonialism, racism, and heteronormativity - faced by these children and youth, their families, and their communities? How do these realities contribute to the neglect, abuse, or various "at risk" behaviours that have led to the children and youth being taken into care?

These questions are too seldom seriously considered, and we find it problematic to conceptualize care as the rehabilitation of minoritized children and youth into unquestioned norms (Griffin, 2004). Of particular concern is the relationship between these norms and the impact of neocolonialism and neoliberalism on minoritized populations. Skott-Myhre (2004), linking neoliberal capitalism to the growing corporatization of social services, reflects that capitalism has "always included the ability to discipline, exploit, assimilate, and exclude various populations” (p. 91). Wade (1995) points out the "very close and mutually supportive relationship between colonialism and the so-called helping professions” (p. 168). In the following section, we demonstrate the links between capitalist ideologies, neocolonialism, the child welfare system's inherent goal to "rehabilitate" children and youth who do not meet normative standards, and the chronic overrepresentation of Indigenous children and youth in care.

\section{The case of Indigenous child welfare}

I do see how these First Nations families, they are so wounded. They really have been told "what you have to offer is not good enough for your own children". To see these families thinking they're not good parents for things like [they] don't have an extra bedroom or their culture is different from white people.

(A residential care provider with 15 years experience)

To illustrate how minoritization operates in Canada's residential care system, in this section we track the minoritization of Indigenous ${ }^{11}$ children, youth, and families over centuries

\footnotetext{
${ }^{11}$ Under the Canadian constitution, “Aboriginal” designates First Nations (both on and off reserve), Metis, and Inuit Peoples. The concept of aboriginality is deeply contested, both for its conflation of hundreds of distinct First Peoples and because their constitution as objects of colonial control has evolved over centuries through concerted settlement and assimilative policies that reproduce their political, economic, and sociocultural exclusion. Therefore, in this article and in our work, we choose instead to use the terms "Indigenous" and "First Peoples" to refer to original societies, not only in a Canadian context, but worldwide. This usage makes visible the impact of European colonialism on over $85 \%$ of the world's Indigenous communities, as well as a growing political solidarity among Indigenous Peoples across the world.
} 
of colonial policies and practices. We explore how neocolonialism contributes to the disproportionate numbers of Indigenous children and youth in our residential care system. We argue that this extreme overrepresentation cannot be considered apart from the history of violence and assimilation that have been critical to the colonial project of building Canada.

Canadian society is dominated by normative social values and practices that have systematically, over many generations, positioned Indigenous cultural and social norms as inferior (Downe, 2005; Lawrence, 2004). Centuries of colonial policies have included: forcefully removing entire communities from their homelands to allow European immigrants to access desired territories; forced sterilizations; conducting scientific experiments on children without consent; deliberately infecting entire communities with lethal diseases such as smallpox; barring Indigenous people from voting, studying, travelling, meeting in groups, practicing their culture, and participating in business; and incarcerating thousands of children in residential schools where they were subjected to multiple physical, spiritual, sexual, emotional, and cultural abuses (Downe, 2005; Lawrence, 2004; Smith, 2004).

Far from occurring only in the past, these colonial policies are deeply embedded in current conditions and ideologies that affect the lives of Indigenous people (Schutte, 2007; Sinclair, 2007). Indeed, Indigenous Peoples in Canada are still governed by the 1876 federal Indian Act, which "rests on the principle that the Aborigines are to be kept in a condition of tutelage and treated as wards or children of the state" (1876 Annual Report of the Department of the Interior, as cited in Indian and Northern Affairs Canada, 2008, p. 172). The racist ideology of the Indian Act characterizes a contemporary context in which Indigenous children continue to be grossly overrepresented in child welfare cases and out-of-home placements (Trocmé et al., 2006). They are currently removed from their homes in such high numbers that the term "Millennium Scoop"12 (Sinclair, 2007) is increasingly used to emphasize the extent of the problem, which Fast and Collin-Vézina (2010) view as "a continuation of the residential school system, only under a different pretence” (p. 128). In the past decade, for example, more Indigenous children were placed in out-of-home care than were enrolled in residential schools at the height of its movement (Blackstock \& Trocmé, 2004). Of any group of children in Canada, Indigenous children and youth also face the highest rates of suicide, ${ }^{13}$ poverty, substandard housing, school dropout, and exposure to various forms of violence, including racism (Aleem, 2009; Blackstock \& Trocmé, 2004; Downe, 2005; Fast \& Collin-Vézina, 2010; Gross, 2003; Sinclair, Bala, Lilles, \& Blackstock, 2004). Despite these risk factors, they are chronically underserved and underfunded. Contrary to popular media representations, on-reserve social services for children and families receive $22 \%$ less funding than services for non-Aboriginal Canadians (Blackstock, Prakash, Loxley, \& Wien, 2005).

\footnotetext{
12 This term is used to invoke a new cycle of the devastation incurred through the "Sixties Scoop" (Ordolis, 2007), the phenomenon of the 1960s in which legislation facilitated the forced removal of staggering numbers of Indigenous children from their homes by government-appointed authorities. Most were placed in white homes, and many were adopted internationally, mainly in the United States and Europe.

${ }^{13}$ While statistics vary by individuals and by community, we emphasize an overall historical pattern and high levels of mobility of Indigenous Peoples across diverse communities.
} 
Some initial efforts have been undertaken to address the overrepresentation of Indigenous children in care. ${ }^{14}$ Most significantly, Indigenous-managed child protection agencies have been created for on- and even off-reserve Indigenous families; however, service delivery remains problematic. For one thing, delegated agencies must comply with provincial legislation, and thus they uphold the state's authority and standards. As noted by de Finney, Green, and Brown (2009), "despite growing efforts to Indigenize child and family services, much of the current research that underlies policy and evidence-based practice remains Euro-Western in its subject matter and methodological orientation” (p. 161). Child welfare should start from a place of transforming the colonial legacies that mediate the lives of Indigenous families. This is not to negate the critical importance of an authority that can intervene in cases of child victimization and abuse. Our argument is not whether such interventions are necessary - they are - but rather that their current design and delivery is clearly not meeting the needs of Indigenous communities and, in fact, is reproducing their very minoritization.

This point is particularly important since leading national studies in child welfare have found that Indigenous families do not have higher rates of physical and sexual abuse than other families (Trocmé, Knoke, \& Blackstock, 2004). Rather, the majority of Indigenous children are taken into care under the "neglect" category - a category that is particularly difficult to assess and that involves more chance of bias than the assessment of abuse. Further, neglect is inextricably tied to poverty because it relates to issues such as frequent moves and the lack of a suitable bedroom, supervision when parents are working multiple jobs, safe housing and adequate clothing and food, and consistency. The fact that these are some of the leading indicators of neglect in Indigenous families points to ongoing practices of social injustice where racialization and systemic inequities are conflated with contemporary middle-class conceptualizations of abuse and neglect. As Hessle and Vinnerljung (2000) emphasize, understandings and definitions of abuse and neglect are always embedded in the cultural context and time in which they are considered. It is clear that the overrepresentation of Indigenous children in care in Canada today can be accounted for, in part, by sociocultural "perceptions of neglect” (Fast \& Collin-Vézina, 2010; Trocmé et al., 2004). These perceptions are compounded by the watching over of Indigenous people by "concerned or caring citizens" that results in disclosures to child protection authorities at rates disproportionate to those of non-minoritized groups (Fast \& Collin-Vézina, 2010). Further, a legislated duty to report neglect positions workers as government agents upholding colonial norms. This obligation inevitably imbues workers with state authority and undermines their attempts to work constructively with families through a collaborative approach that engages families' expertise and considers the social and historical contexts of their struggles.

Consider the following example, the subject of a 2009 investigation report by British Columbia’s Representative for Children and Youth: A two-month-old baby boy lived in a small First Nation community in B.C. in which his family had significant cultural ties. Due to

\footnotetext{
${ }^{14}$ Many initiatives are underway across Canada to integrate the voices of Indigenous communities, including children and youth, in a transformation of child welfare from the ground up. See, for example, the First Nations Child and Family Caring Society (www.fncfcs.com/), the Indigenous Child Welfare Research Network (web.uvic.ca/icwr), the Mamow Sha-way-gi-kay-win project (www.northsouthpartnership.com), and the Yellowhead Tribal Services Agency (www.ytsa.ca).
} 
"historical child protection issues" that involved relatives in the home where the parents and baby were staying, the home was judged unsafe and the parents were asked to find other housing. When the social worker visited the parents, the "child looked well and both of his parents were attentive to their baby” (Representative for Children and Youth, 2009, p. 11). The child's mother stated that they planned to reside with a close relative while they were looking for off-reserve housing, as no housing was available on reserve apart from sharing with extended family. She was eligible to receive social assistance from her band as long as she lived on reserve, but no onreserve homes were available. Over 200 people were on the list for housing on this reserve, and many homes accommodated more than a dozen people, "not by choice, but out of necessity" (p. 35). When the parents were unable to find other housing, the baby was removed from their care. In the first three months after being apprehended, the baby was placed in three different foster homes, all of them non-First Nations, even though the local delegated Aboriginal agency had secured a First Nations caregiver. During his last placement, the infant was admitted to hospital with a severe brain injury. The foster home was investigated and closed, and one of the foster parents charged, when it was determined that the baby had been shaken. He now lives with cerebral palsy, epilepsy, and significant sight and hearing impairments. He will require lifelong support. He has since been returned to his parents, who now live in subsidized housing and who, ironically, have now been deemed capable of caring for him.

The report of the Representative for Children and Youth (2009) states that the child welfare system entered this child’s life in response to child protection reports, but:

its ongoing impact on the child's life related to his parents' poverty and inability to afford housing that met the ministry's standards. There was no suggestion that this baby's parents were abusive, or neglectful of his care, or unsafe . . . . There was no clear focus on assisting this young family in solving the key problem that prevented them from living with their baby - lack of a safe home. As a result, the baby was separated from his parents, his community and his culture, and he was critically injured [while in foster care]. (p. 34)

The report goes on to state that "immediate income assistance, a short-term housing grant and positive supports would have been a sensible and appropriate approach . . . for young Aboriginal parents willing to and capable of caring for their infant son” (p. 53).

Although this case had a particularly tragic outcome, it is not an anomaly; it represents a problematic cycle of intervention that negatively impacts thousands of Indigenous families. The case tellingly illustrates the interaction of every factor we have described in this article, namely the power of normative standards of wellness, development, and family to fuel the "need" to remove minoritized children and youth from their families, communities, and cultures. Is it a coincidence that roughly half of child protection cases occur in families who are or have been on income assistance, and that half are also Indigenous (Representative for Children and Youth, 2009)? How is it that, due to underfunding, apprehensions are too often the only child welfare service provided to Indigenous communities? How is it that the preferred intervention perpetuates a cycle of cultural dislocation, poverty, and family alienation? Trocmé et al. (2006) state that the fact that "neglect is the primary type of child maltreatment experienced by First Nations children calls for a reorientation of child welfare research, policy and practice to develop culturally sensitive and effective responses” (p. 12). From our perspective, a reorientation is 
International Journal of Child, Youth and Family Studies (2011) 3 \& 4: 361-384

indeed needed, one in which we completely rethink the structure and function of child welfare values and services in Canada. Otherwise, Indigenous families will continue to experience child welfare contact as "intrusive and culturally inappropriate" (Simard, 2009, p. 44), limiting the capacity to build meaningful partnerships that might sustain more comprehensive social change strategies. Interventions to address the broader inequities that underlie neglect would do much to redress the centuries-old legacies of colonial policies that have so deeply damaged the sociocultural, economic, and political structures of First Peoples’ societies. Indigenous communities and advocates argue that in order to be effective, such transformations must honour the self-determination and diverse knowledge and needs of Indigenous nations (Simard, 2009).

\section{Problematizing residential care practice}

We had a transgender youth in one of our group homes, and that individual was isolated to their own bedroom, whereas everyone else in the home shared a room with someone who was the same sex as them. The staff didn't really support that youth in the same way [as they did other youth]. That youth was often bullied by staff and other youth.... The staff didn't agree with

the trans thing at all. They thought it was the cause of all of his problems, like if he wasn't [transgendered], he wouldn't be so messed up. I was like, hello, maybe the consistent negative and abusive reactions he gets for being a trans guy are the cause of his problems.

(A residential care practitioner with nine years experience)

What is most troubling about minoritization, as the examples we have shared in this article demonstrate, is the cycle of social exclusion, state intervention, and institutionalization it reproduces. It is through this logic that the residential care sector sustains an entire industry of programs and policies designed to help colonized populations cope with colonialism, rather than challenging its very premise. These critical links are too easily lost in the constant demands of everyday practice. Too often children and youth become stereotypical emblems of the "bad" part of town, the "problem" family, or the "resistant" cultural group. "At risk" - which we understand to mean risk embedded in conditions of social inequity - becomes understood as an inherent characteristic rather than a result of structural inequities. Their ghettoization along intersecting lines of class, gender, sexuality, ability, and race leads to the paradox that minoritized communities are at once hyper-monitored by service providers, yet critically underserved.

Burman (2003) stresses that that "the very articulation of the position of 'other' implies the marking of differences, whose explicit or implicit devaluation demands rectification" (p. 294). Situated as "residential care experts", practitioners become administrators of the dominant paradigm of social order who monitor clients, employing our professional gaze to label and treat. Thus residential care marks and individualizes the differences of minoritized children, youth and families so that they can be readily categorized as in need of professional help. This categorization serves in turn to justify necessary interventions, evidencing how we, as practitioners, benefit from practices that serve our professional interests by maintaining the demand for our specific skills and training (Kivel, 2007). Schutte (2007) argues that, "we must assume moral responsibility in acknowledging the degree to which any of us is ideologically or materially complicit with the power and goals of neo-liberal global capitalism” (p. 171). Since, as Gharabaghi (2009) argues, social service work is implicated in social injustice because it 
depends on it for its very existence, are social justice and social care destined to be mutually exclusive?

It is this issue of complicity - whether conscious or not - that warrants a critical unpacking. It is not our intention to individualize the problem of minoritization and place blame on individual service providers or agencies, but rather to make visible our involvement in the systemic structures of minoritization as they operate under neoliberalism and neocolonialism. Gharabaghi and Krueger (2010) explain that, "our interventions with children, youth and families increasingly resemble those undertaken by the very formal and informal institutions that have failed them in the first place” (p. 29). And so we ask, what role might practitioners play in challenging these dynamics? Given the pervasive historical silencing of minoritization, we want to acknowledge how difficult it is for practitioners to incorporate a critical analysis of the neoliberal and neocolonial agenda in which their work is embedded. As discussed by Reynolds (2010), policies at all levels often restrict the ability of front line workers to act creatively and in line with their ethics, and the notion prevails that the policies of residential settings cannot be changed from the front lines. No matter how dedicated or passionate about our work we might be, we often come face to face with the deeply embedded nature of these barriers, the difficulty of building strategic partnerships, a lack of knowledge, skills, resources, and supports to enact change, and backlash when we challenge the status quo. When this happens, our work is depoliticized and its potential for lasting social change is restricted.

Notions of diversity and cultural competence - so prevalent in the human services, including child and youth care - are inadequate to address these tensions. The "culturally competent" practitioner is a contested concept because it asserts that diversity is something to be figured out in a limited set of individualized competencies. Such practice ideals too often ignore histories of colonization; they portray our social landscape through a neoliberal lens as a multicultural land of equal opportunity where culture and difference are celebrated and embraced and where power relations - such as those we have discussed in our examples - are rendered invisible (Robinson, 2004). This invisibilization of power relations is of great concern given that notions of diversity competency are often foundational to the goals of therapeutic intervention and rehabilitation.

Another problem with the idea of diversity competence is that it negates the multiplicities of any given culture; it suggests that cultures are natural, static, mutually exclusive entities that can be pinned down in "culturally sensitive" programming. This approach, typical in assessments and treatment planning, assumes that a child, youth, or family will be able to describe their "culture" in coherent and accessible terms, leading to stereotyping and tokenism. An emphasis on cultural competence also often renders invisible the many aspects of diversity that exist outside of culture, since the term "culture" itself is vague and tends to be associated only with factors like ethnicity, language, and/or religion while ignoring diversities of gender, sexuality, and ability, for example (Johnson \& Munch, 2009). The culturally themed dinners and celebrations that often occur in residential settings tend to oversimplify cultural complexities in this way. While paying attention to the cultural histories, values, and contexts of all children and youth is critical to effective connections, cultural safety must address structural inequities since the barriers that affect the lives of those in residential care are not cultural, but systemic and structural. 
Yet level systems, token economies, and social skills trainings, for example, all legacies of dated behavioural and social learning theories that tend to ignore broader macro-level forces, continue to be used in residential and treatment programs as means of socializing children and youth in a manner deemed to be in their best interest. These interventions send messages that the minoritized experience is the client's responsibility, and the therapeutic benefit is therefore lost. Because the social realities that underpin the client's problem behaviour remain hidden and thus unaddressed in these approaches, practices of this nature can be seen as acts of social regulation or control (Chantler, 2005). As Burman (2003) points out, "talk of difference is not about all differences, but about those that, within dominant discourses, are marked . . . as deviant or deficient” (p. 294).

Let us consider again the goals of residential settings: They centre on keeping children and youth "safe" and "healthy," and on working in individuals' best interests to support their integration into society. Burman (2003) points out that a focus on social integration tends to "overlook a critical appraisal of precisely what it is those designated 'excluded' are to be included into" (p. 294). The agency of children and youth is rendered invisible in this system and their attempts to resist or speak back to the norms being forced on them are often labelled as antisocial or rebellious. Instead, interventions are designed to help them adjust their "maladaptive", "harmful”, or "problem" behaviours to fit into dominant societal norms. This includes ignoring or pathologizing acts of resistance and labelling them as disordered or deficient. It also serves to depoliticize children, youth, and families, and silences their perspectives on their own lives and care.

For example, the scenario that the residential care practitioner describes in the quote that begins this section relates the labelling of a transgendered youth in a group home. The staff's discomfort with nonconforming expressions of gender and sexuality place a young person in a position of being judged and victimized within the therapeutic milieu. The youth's actions and identity are not viewed positively as a form of resistance against normative gender roles and expectations, but are pathologized and discouraged, thought ultimately to be the root cause of the youth's difficulties. Davis, Saltzburg, and Locke (2009) explain that, "the portrayal of gay, lesbian, bisexual and transgender (GLBT) lives as a normative variance of human experience is often overshadowed by the disparaging imagery historically attached to being GLBT” (p. 1030). The care the young person receives in this setting is influenced by a deep-seated belief that nonconforming gender expressions are something to be corrected. Even if this belief is only expressed covertly, it fails to acknowledge the role of heteronormativity in creating and maintaining the difficulties that confront the young person.

Skott-Myhre (2004) asserts that rooted within the dominant Euro-Western paradigm of the helping professions is the task of forced assimilation. He argues that human services work is inherently colonial; its central goal is to control and discipline bodies and minds to "comply with the interests of the nation, the corporation, the family, or the agency" (p. 90). Arieli (1997, as cited in Skott-Myhre, 2004, p. 90) stresses that the worker's task is to bring together those who are "properly socialized" with those "who are not"; the ones who know the "proper" social codes (i.e., care providers) are expected to generate change in the ones who do not (i.e., those in care) by intervening in the course of their maturation. As practitioners taking up the dominant (white, 
International Journal of Child, Youth and Family Studies (2011) 3 \& 4: 361-384

heterosexual, middle-class, able) paradigm of the field, we are precluded from seeing ourselves inside this privileged category, as it is rendered invisible through the social construction of care as inherently benevolent and unproblematic. What greater altruistic position than to care for the most marginalized of children and youth? Our position of power makes the struggle to "make sense from within” (Davies, 2000, p. 23) unnecessary, because the legitimacy of our role is taken for granted through the assumptions that relational care is unproblematic.

Our participation in the regulation of our clients is supported by the planned environments we create, the training tools we employ, and the instruments we use to measure the success and failure of interventions. These are "mechanisms of power ... disposed around the abnormal individual, to brand and alter him [or her]” (Foucault, 1977, p. 199). Walkerdine (1984) implicates all learning environments in this process:

The parameters of practice are given by the common sense of child development which is everywhere, in apparatuses from teacher training, to work cards, to classroom layout. The apparatuses themselves provide a norm, a standard of good and possible pedagogy. We would find no classroom [or program/intervention] which stood outside the orbit of some constellation of discursive and administrative apparatuses. (p. 162)

Within the dominant neoliberal, neocolonial apparatuses, the success of the helping relationship is contingent on the individual's or family's choice to work either "with us or against us". Discourses of diversity inundate us with a rhetoric of equality that fails to acknowledge both the constructed quality of difference and the consequences this construction has in the lived experiences of minoritized groups. Burman (2003) argues that, "talk of difference or diversity codes for power inequalities, but precisely through this euphemistic coding it loses its critical analytical edge” (p. 295). Only through our active interrogation of these coding processes can we begin to move from a regulatory practice to a radical praxis of social justice concerned with disrupting hegemonic power across the multiple sites of our work.

\section{A new praxis of social justice}

So they're all, teachers and stuff, like, oh talking about racism is too hard, it confuses the kids so we should not do that to them, like we're too dumb to understand what happens to us every day? I think it's more like an opposite situation, like I mean they don't want to talk or they're scared about racism because they're the group of power. They don't give us . . credit that we understand and yeah we need to talk about it!

(Priya, 16, social justice activist)

For practitioners to challenge the primacy of neoliberalism and neocolonialism in all its many effects and forms, Skott-Myhre (2004) states, we must "step outside the frameworks of colonial youth work and engage a different set of ideas, beliefs, and practices” (p. 92). To achieve this goal, it is essential "to decolonize youth work . . . to engage in what might be called radical youth work” (p. 92). The same ideas apply to radical social justice praxis in residential care. Skott-Myhre stresses that radical human services work signifies an intentional shift away 
from safety and the normative force that safety implies. Letting go of the safety provided by normative standards reveals the complexity of social advocacy and activism. As Jones de Almeida (2007) underscores, "radical social change ... is much more than just 'social' - it is also personal and political, and about money and privilege, and about sexuality, race, and gender, and about the relationship between our minds, bodies, and spirit” (p. 194). From this perspective, social change is complicated, multifaceted, and politicized. It cannot be reduced to individualized, singular definitions and prescriptive measures. Given our assertion that critical analysis is essential to challenge minoritization, in our concluding pages we explore in more detail what a multifaceted social justice praxis of residential care might look like.

Residential care comprises a tremendous diversity of practice settings, approaches, and practitioners. We are aware of this inherent diversity, but our goal here has been to focus on systemic, historical issues that shape our field. We recognize that, even in the familiar confines of a given field, no absolute footing exists for any of us; at any moment in any given context, we may find ourselves dancing along the spectrum of social change versus social regulation, implicated in structural inequities while we work to unravel them. Our efforts to extricate these complexities will inevitably make visible their contradictions - and the impossibility of addressing every issue in detail. For instance, in this article we have focused on minoritization in general, rather than on specific debates within each of the fields of race, gender, disability, and sexuality studies. Before moving on, we want to emphasize that these discussions are equally important, but they exceed the scope of this article.

The tension between social justice as both ethical obligation and unattainable ideal is a tangible reality in our practice and our theoretical work. Reynolds (2010) advances an ethic of solidarity, while cautioning practitioners not to step into righteousness or "replicate the kinds of dominance we hope to alleviate; accommodating people to lives of poverty, and participating in practices that can serve as social control” (p. 2). For us, as queer and First Nations practitioners and researchers, this focus is not only about social justice for those with whom we work, but a matter of personal struggle for us and our communities. The dilemma of how to translate a commitment to social justice into action has been taken up by others in child and youth care (among others, see Gharabaghi, 2009; Newbury, 2009; Skott-Myhre, 2005, 2008) who have argued that socially just practice should include a politicized, systemic focus. Our responsibility to care operates not only in everyday practice with individuals, but extends to political action and other forms of advocacy. Reconceptualizing care as both an applied and political endeavour has helped expand definitions of what it means to work in the best interest of children, youth, families, and communities, including our own.

Despite these efforts, much work remains. Social justice too often remains peripheral, rather than being a central component of our practice frameworks (Newbury, 2009). While projects like the North American Certification Project or NACP (Mattingly \& Stuart, 2002) draw attention to the importance of concepts like advocacy and diversity in practice, a commitment to social justice is not explicitly articulated in large-scale efforts to define or standardize practice in the North American context, nor is an understanding of how processes of minoritization influence our work and the lives of children, youth, and families. Consequently, there is an urgent need to document the diverse and creative ways practitioners engender social justice in their practice. In our work on minoritized girlhood, we provide our own examples (de Finney, 
Loiselle, \& Dean, in press) of how social justice might be enacted both explicitly and subversively at the micro level of practice. But we also argue that an exclusive focus on individualized justice-doing (Reynolds, 2010) risks reifying the myth that front line workers are powerless to generate broader forms of social change. Equally critical to individual efforts is the sort of analysis we and others in this volume have mapped out, informed by critical theories that do not come out of normative Euro-Western psychological traditions. Such theorization provides urgently needed counter-hegemonic understandings of minoritization by linking everyday practice to structural power systems such as colonialism. While it is not in itself sufficient, we strongly feel that the sort of transtheoretical analysis presented here is integral to addressing the failure of residential care interventions to target historical social inequities. We contest the all too familiar concern in an applied field such as ours, that critical analysis is a barrier to effective practice. From our multiple positions as practitioners, researchers, and activists, we see that ignoring links between social inequities and the realities of children and youth in care reasserts the dominance of Euro-Western psychological norms that is so harmful to the communities we work with. As Priya reminds us at the beginning of this section, discomfort with critical analysis is exactly the kind of thinking that renders minoritization so difficult to name and contest, and that reproduces the very conditions practitioners hope to address. In other words, if we do not name it, how will we work collectively to change it?

\section{Conclusion}

Critically examining the work to which so many of us dedicate ourselves can be uncomfortable. But as Thomas and Green (2007) assert in their exploration of socially just practice from an Indigenous perspective, social justice work "should always be complicated and uncomfortable" (p. 91). We can understand this to mean that, while we are aware of the contradictions and messiness of our efforts to explore social justice praxis, we recognize that we cannot not do the work. Addressing power "requires a commitment to complex analysis and the letting go of wanting everything to be simple. Segregation simplifies; integration requires that we come to terms with multiple ways of knowing, of interaction” (Reynolds, 2010, p. 53).

Given our desire to trouble the borders between realms of practice and theorization, and our disinclination to adopt one-dimensional solutions, how do we move out of paralyzing dichotomies and into a new (albeit imperfect) understanding of praxis that offers room for multiple, overlapping strategies of social change? We tackle this question not in an attempt to provide a definitive resolution, but in the spirit of expanding and making more complex what counts as social justice, and, by extension, what is considered effective residential care practice. We hope this is only the beginning of an evolving discussion that includes many voices and strategies. Gharabaghi and Krueger (2010) emphasize that a "new politic" of practice is warranted to address the reflective nature of social justice in our practice. This, they argue, would focus practitioners and academics on the social realities that impact our work and would better prepare them to provide ethical care for children, youth, and families. We see this as an urgently needed step forward. Without it - without a critical unpacking of minoritization and relations of power - we will continue to walk through the doors of residential care settings and see the same faces staring back at us. 
International Journal of Child, Youth and Family Studies (2011) 3 \& 4: 361-384

\section{References}

Access Alliance. (2007). Multicultural health and community services: Research. Retrieved January 15, 2011, from http://accessalliance.ca/sites/accessalliance/files/documents/AnnualReport0607

Aleem, R. (2009). International human rights law and Aboriginal girls in Canada: Never the twain shall meet. Justice for Girls International. Retrieved from: http://www.justiceforgirls.org/international_hr/index.html

Anglin, J. (2002). Pain, normality and the struggle for congruence: Reinterpreting residential care for children and youth. Binghamton, NY: Hawthorne.

Blackstock, C., Prakash, T., Loxley, J., \& Wien, F. (2005). Wen:de: We are coming to the light of day. Ottawa, ON: First Nations Child \& Family Caring Society of Canada.

Blackstock, C., \& Trocmé, N. (2004). Community-based child welfare for Aboriginal children: Supporting resilience through structural change. In M. Ungar (Ed.), Pathways to resilience: A handbook of theory, methods, and interventions (pp. 1-28). Thousand Oaks, CA: Sage.

Burman, E. (1994). Deconstructing developmental psychology. London: Routledge.

Burman, E. (2003). From difference to intersectionality: Challenges and resources. European Journal of Psychotherapy, Counseling and Health, 6(4), 293-308.

Burns, M. (2006). Healing spaces: The therapeutic milieu in child care and youth work. Toronto: Child Care Press.

Centre for Addiction and Mental Health. (2004). Better dead than queer: Youth suicide and discrimination in a heterosexual world. Retrieved from:

http://www.camh.net/Publications/Cross_Currents/Winter_2004/deadqueer_crcuwinter0405.html

Chantler, K. (2005). From disconnection to connection: Race, gender and the politics of therapy. British Journal of Guidance \& Counselling, 33(2), 239-256. 
International Journal of Child, Youth and Family Studies (2011) 3 \& 4: 361-384

Chantler, K., \& Smailes, S. (2004). Working with differences: Issues for research and counselling. Counselling \& Psychotherapy Research, 4(2), 34-39.

Charles, C. E. (2010). Complicating hetero-femininities: Young women, sexualities and "girl power” at school. International Journal of Qualitative Studies in Education, 23(1), 33-47.

Child Welfare League of Canada. (2003). Children in care in Canada: A summary of current issues and trends with recommendations for future research. Retrieved from: http://www.cecw-cepb.ca/publications/574

Davies, B. (2000). Body of writing 1990-1999. Walnut Creek, CA: AltaMira.

Davis, T. S., Saltzburg, S., \& Locke, C. R. (2009). Supporting the emotional and psychological well-being of sexual minority youth: Youth ideas for action. Children and Youth Services Review, 31(9), 1030-1041.

de Finney, S., Green, J., \& Brown, L. (2009). Towards transformational research for and with Indigenous communities: The new British Columbia Indigenous Child Welfare Research Network. First Peoples Child \& Family Review, 4(2), 161-164.

de Finney, S., Loiselle, E., \& Dean, M. (in press). Bottom of the food chain: The minoritization of girls in child and youth care. In A. Pence \& J. White (Eds.), Critical perspectives in child and youth care: Working the borders of pedagogy, practice and policy (pp. 92121). Vancouver, BC: UBC Press.

Downe, P. J. (2005). Aboriginal girls in Canada: Living histories of dislocation, exploitation, and strength. In Y. Jasmin, C. Steenbergen, \& C. Mitchell (Eds.), Girlhood: Redefining the limits (pp. 1-14). Montreal, QC: Black Rose.

Family Builders Adoption Network. (n.d.). My pride and joy: The facts about LGBTQ youth in foster care. Retrieved from: http://www.familybuilders.org/fostercare/pride_and_joy.html

Fast, E., \& Collin-Vézina, D. (2010). Historical trauma, race-based trauma and resilience of Indigenous Peoples: A literature review. First Peoples Child \& Family Review, 5(1), 126-136. 
International Journal of Child, Youth and Family Studies (2011) 3 \& 4: 361-384

Fechter-Leggett, M. O., \& O’Brien, K. (2010). The effects of kinship care on adult mental health outcomes of alumni foster care. Children and Youth Services Review, 32(2), 206-213.

Foucault, M. (1977). Discipline and punish: The birth of the prison (A. Sheridan, Trans.). New York: Random House. (Original work published 1975)

Foucault, M. (1978). The history of sexuality (Vol. 1). New York: Vintage Books.

Foucault, M. (1980). Power/knowledge. Brighton, UK: Harvester.

Frensch, K. M., \& Cameron, G. (2002). Treatment choice or last resort? A review of residential mental health placements for children and youth. Child and Youth Care Forum, 31(5), 307-339.

Galabuzi, G. E. (2004). Social exclusion. In D. Raphael (Ed.), Social determinants of health (pp. 235-252). Toronto: Canadian Scholars Press.

Gharabaghi, K. (2009). Social justice unpacked: A response to Newbury. Relational Child and Youth Care Practice, 22(4), 29-32.

Gharabaghi, K., \& Kruger, M. (2010). A new politic in child and youth care. Relational Child and Youth Care Practice, 23(3), 27-39.

Grewal, I. (2005). Transnational America: Feminisms, diasporas, neoliberalisms. Durham, NC: Duke University Press.

Griffin, C. (2004). Good girls, bad girls: Anglocentrism and diversity in the constitution of contemporary girlhood. In A. Harris (Ed.), All about the girl: Culture, power and identity (pp. 29-44). New York: Routledge.

Gross, E. (2003). Native American family continuity as resistance: The Indian Child Welfare Act as legitimation for an effective social work practice. Journal of Social Work, 3(1), 31-44.

Harley, D. A., Jolivette, K., McCormick, K., \& Tice, K. (2002). Race, class, and gender: A constellation of possibilities with implications for counselling. Journal of Multicultural Counseling and Development, 30(4), 216-238. 
International Journal of Child, Youth and Family Studies (2011) 3 \& 4: 361-384

Hernandez, D., \& Rehman, B. (2002). Colonize this! Young women of color on today's feminism. New York: Seal Press.

Hessle, S., \& Vinnerljung, B. (2000). Child welfare in Sweden. An overview. Stockholm Studies in Social Work, No. 15, Stockholm University, Sweden.

Indian and Northern Affairs Canada. (2008). Treaty research report-Treaty 3 (1873). Ottawa: Department of Indian and Northern Affairs Canada. Retrieved from: http://www.ainc-inac.gc.ca/al/hts/tgu/pubs/t3/tre3-eng.asp

Johnson, Y. M., \& Munch, S. (2009). Fundamental contradictions in cultural competence. Social Work, 54(3), 220-231.

Jones de Almeida, A. (2007). Radical social change: Searching for a new foundation. In INCITE! Women of Color Against Violence (Ed.), The revolution will not be funded: Beyond the non-profit industrial complex (pp. 185-197). Cambridge, MA: South End Press.

Kivel, P. (2007). Social service or social change? In INCITE! Women of Color Against Violence (Ed.), The revolution will not be funded: Beyond the non-profit industrial complex (pp. 129-149). Cambridge, MA: South End Press.

Lavergne, C., Dufour, S., Trocmé, N., \& Larrivee, M. (2008). Visible minority, aboriginal, and caucasian children investigated by Canadian protective services. Child Welfare, 87(2), 59-76.

Lawrence, B. (2004). “Real” Indians and others: Mixed-blood urban native peoples and Indigenous nationhood. Vancouver, BC: UBC Press.

Maier, H. (1967). Institutional care of deprived children. Studies: An Irish Quarterly Review, 56(2), 17-27.

Mattingly, M., \& Stuart, C. (2002). The North American Certification Project (NACP) competencies for professional child and youth work practitioners. Journal of Child and Youth Care Work, 17, 16-49.

Miles, R. (1997). Racism after 'race relations.' London: Routledge. 
International Journal of Child, Youth and Family Studies (2011) 3 \& 4: 361-384

Mohanty, C. T. (2003). Feminism without borders: Decolonizing theory, practicing solidarity. Durham, NC: Duke University Press.

Morss, J. R. (1996). Growing critical: Alternatives to developmental psychology. London: Routledge.

Newbury, J. (2009). Contextualizing child and youth care: Striving for socially just practice. Relational Child and Youth Care Practice, 22(4), 20-29.

Ordolis, E. (2007). A story of their own: Adolescent pregnancy and child welfare in Indigenous communities. First Peoples Child \& Family Review, 3(4), 30-41.

Pereira, A. (2008). Does multiculturalism recognise or 'minoritise' minorities? Studies in Ethnicity and Nationalism, 8(2), 349-356.

Phoenix, A. (2004). Neoliberalism and masculinity: Racialization and the contradictions of schooling for 11- to 14-year-olds. Youth \& Society, 36(2), 227-246.

Renold, E., \& Ringrose, J. (2008). Regulation and rupture: Mapping tween and teenage girls' resistance to the heterosexual matrix. Feminist Theory, 9(3), 313-339.

Representative for Children and Youth. (2009, July). Housing, help and hope: A better path for struggling families. Victoria, BC: Author.

Reynolds, V. (2010). Doing justice as a path to community sustainability. Doctoral dissertation, Universiteit van Tilburg, Tilburg, Netherlands. Retrieved from: http://www.taosinstitute.net/

Robinson, K., \& Davies, C. (2007). Tomboys and sissy girls: Young girls’ negotiations of femininity and masculinity. International Journal of Equity and Innovation in Early Childhood, 5(2), 17-31.

Robinson, T. L. (2004). The convergence of race, ethnicity, and gender (2nd. ed.). Upper Saddle River, NJ: Pearson/Merrill Prentice Hall. 
International Journal of Child, Youth and Family Studies (2011) 3 \& 4: 361-384

Schutte, O. (2007). Postcolonial feminisms: Genealogies and recent directions. In L. M. Alcoff \& E. F. Kittay (Eds.), The Blackwell guide to feminist philosophy (pp. 165-176). Malden, MA: Blackwell.

Simard, E. (2009). Culturally restorative child welfare practice - A special emphasis on cultural attachment theory. First Peoples Child \& Family Review, 4(2), 44-61.

Sinclair, M., Bala, N., Lilles, H., \& Blackstock, C. (2004). Aboriginal child welfare. In N. Bala, M. Zapf, J. Williams, R. Vogl, \& J. Hornick (Eds.), Canadian child welfare law: Children, families, and the state (pp. 199-244). Toronto: Thompson.

Sinclair, R. (2007). Identity lost and found: Lessons from the sixties scoop. First Peoples Child \& Family Review, 3(1), 65-82.

Skott-Myhre, H. A. (2004). Radical youthwork: Creating a politics of mutual liberation for youth and adults. Journal of Child and Youth Care Work, 19, 89-94.

Skott-Myhre, H. (2005). Towards a minoritarian psychology of immanence and a psychotherapy of flight: Political meditations on the society of control. Parallax, 11(2), 44-59.

Skott-Myhre, H. A. (2008). Youth and subculture as creative force: Creating new spaces for radical youth work. Toronto: University of Toronto Press.

Smith, A. (2004). Conquest: Sexual violence and American Indian genocide. Cambridge, MA: South End Press.

Statistics Canada. (2003). Ethnic diversity survey: Portrait of a multicultural society. Ottawa, ON: Author.

Strong-Boag, V. (2007). Children of adversity: Disabilities and child welfare in Canada from the nineteenth to the twenty-first century. Journal of Family History, 32(4), 413-432.

Thomas, R., \& Green, J. (2007). A way of life: Indigenous perspectives on anti-oppressive living. First Peoples Child \& Family Review, 3(1), 91-104.

Trieschman, A. E., Whittaker, J. K., \& Brendtro, L. K. (1969). The other 23 hours. New York, NY: Aldine de Gruyter. 
International Journal of Child, Youth and Family Studies (2011) 3 \& 4: 361-384

Trocmé, N., Knoke, D., \& Blackstock, C. (2004). Pathways to the overrepresentation of Aboriginal children in Canada's child welfare system. The Social Service Review, 78(4), 577-600. Chicago, IL: University of Chicago Press.

Trocmé, N., MacLaurin, B., Fallon, B., Knoke, D., Pitman, L., \& McCormack, M. (2006). Mesnmimk Wasatek: Catching a drop of light. Understanding the overrepresentation of First Nations children in Canada's child welfare system: An analysis of the Canadian incidence study of reported child abuse and neglect (CIS-2003). Toronto, ON: Centre of Excellence for Child Welfare.

UNICEF Canada. (2010). The UNICEF Innocenti Report Card 8. Retrieved from http://www.unicef.ca/portal/SmartDefault.aspx?at=2250

Wade, A. (1995). Resistant knowledges: Therapy with Aboriginal persons who have experienced violence. Canadian Western Geographical Series, 31, 167-206. Vancouver, BC: UBC Press.

Walkerdine, V. (1984). Developmental psychology and the child centred pedagogy. In J. Henriques (Ed.), Changing the subject: Psychology, social regulation and subjectivity (pp. 153-202). London: Methuen.

White, J. (2007). Knowing, doing and being in context: A praxis-oriented approach to child and youth care. Child and Youth Care Forum, 36(5-6), 225-244. 